\title{
Materiais didáticos para o ensino de física no nível fundamental por meio de plataformas eletrônicas
}

\author{
Teaching Materials for Physical Education in Elementary School using \\ Electronic Platforms
}

\begin{abstract}
Fábio Lombardo Evangelista*, Jucimar Peruzzo ${ }^{\dagger}$
Coordenação Geral de Ensino - Instituto Federal Catarinense, campus Concórdia.
\end{abstract}

\begin{abstract}
Resumo
Este trabalho propõe uma sequência didática composta por 4 encontros para trabalhar o conteúdo "momento de alavanca" no ensino fundamental e introdução à lógica de programação. Pode ser aplicado a estudantes do 50 ao 90 ano do ensino fundamental. As aulas foram instrumentalizadas por um braço robótico construído em impressora 3D e controlado pela tecnologia Arduino. Também houve o estudo da lógica de programação, mediante o uso do programa computacional Scratch, instalado em uma plataforma eletrônica Raspberry Pi. A mediação sugerida visa promover cinco relações pedagógicas: aluno-professor, aluno-aluno, aluno-ambiente, aluno-saber científico e aluno-tecnologia. Com a aplicação da sequência didática proposta, pode-se perceber que as relações citadas, além de motivar os alunos, permitem uma considerável influência na reelaboração conceitual dos assuntos estudados e uma melhor compreensão da lógica de programação.
\end{abstract}

Palavras-chave: Sequência didática. Impressão 3D. Arduino. Raspberry Pi.

*fabio.evangelista@ifc.edu.br

†jucimar.peruzzo@ifc.edu.br 


\begin{abstract}
This work refers to the creation of a didactic sequence composed of 4 classes to work moment arm in elementary education and introduction to programming logic. It can be applied to students in grades 5 through 9 of elementary school. The classes were instrumented by a robotic arm built in $3 D$ printer and controlled by Arduino technology. There was also the study of programming logic, using the Scratch computer program installed in an electronic platform Raspberry Pi. The suggested mediation aims to promote five pedagogical relationships: student-teacher, studentstudent, student-environment, student-scientific knowledge and student-technology. With the application of the proposed didactic sequence, it can be noticed that the mentioned relations, besides motivating the students, allows a considerable influence on the conceptual reworking of the studied subjects and a better understanding of the programming logic.
\end{abstract}

Keywords: Didactic sequence. 3D printing. Arduino. Raspberry Pi.

\title{
I. INTRODUÇÃO
}

Conforme Alves Filho (2000a), uma má ação docente, embasada em metodologias inadequadas e desmotivadoras, robustecem os obstáculos na transposição do senso comum para o científico. Os principais impedimentos encontrados no estudo de Física estão relacionados à escassez de instrumentos concretos e metodológicos adequados ao ensino. Uma opção, neste caso, é variar os recursos didáticos por meio de instrumentos tecnológicos para o ensino de Física.

Oliveira et. al (2017) fala que as potencialidades atribuídas aos instrumentos não estão atreladas à sua exclusiva inserção no ambiente escolar. Esta entrada instrumental no contexto de sala de aula precisa ser analisada em comunhão com a prática docente. Segundo Sampaio (2010, p.19) "é necessário que o professor conheça, utilize, interprete e domine criticamente a tecnologia para não ser dominado por ela". A tecnologia deve ser inserida na sala de aula como um instrumento facilitador, uma ferramenta detentora de significado, servindo de mediação ao saber científico (ALVES FILHO, 2000b). Conforme Otero (2005), quando se pretende inovar, é preciso ter a compreensão de que a tecnologia não deve ser mero artefato, mas sim um instrumento pedagógico significativo ao processo de ensino e aprendizagem.

Nesse caso, para trabalhar situações e fenômenos do mundo real no contexto escolar, tecnologias como o Arduino, o Raspberry PI e a impressão 3D apresentam uma boa combinação (OLIVEIRA et al., 2017), pois possuem vastas explicações e aplicações acessíveis nas mídias digitais, o que acaba por oportunizar ir além do universo escolar.

Para Bennett, Maton e Kervin (2008) os novos alunos, denominados nativos digitais ou geração conectada não aprendem da mesma forma que as gerações anteriores; isto porque, atualmente, eles aprendem a partir de experiências, possuem habilidades em multitarefas e estão adaptados às tecnologias de informação e comunicação para se conectarem com outras pessoas. 
Prensky (2001, p.1) fala que "os alunos sofreram mudanças radicais e não são mais as pessoas para as quais o sistema educacional foi modelado para ensinar". Essas afirmações apontam para a necessidade de tornar o ensino de física mais significante, motivador, desafiante e atraente ao ambiente escolar, e para isso a tecnologia surge como uma possível alternativa.

O objetivo principal deste artigo é a construção de uma sequência didática para trabalhar o conceito de momento de alavanca e lógica de programação no ensino fundamental, permeada por aparatos eletrônicos controlados por Arduino, um braço robótico impresso em 3D e um Raspberry Pi com o programa Scratch instalado.

O presente artigo está dividido em seis seções: a seção dois apresenta a fundamentação teórica; na seção três é descrita a proposta tecnológica que se tem como base; a seção quatro detalha a sequência didática proposta; a seção cinco traz dicas para realizar a sequência didática; e por fim, a seção 6 apresenta as considerações finais.

\section{FundAMENTAÇão TEÓRICA}

Durante o planejamento das aulas, procurou-se fundamentar as relações pedagógicas entre os personagens de um contexto de sala de aula em dois autores principais. Oliveira et al. (2017) defende que estas relações devam ocorrer entre: Aluno Aluno; Aluno Professor; Aluno Tecnologia e Aluno Ambiente. Alves Filho (2000b) defende que, durante o processo de ensino e aprendizagem, há um diálogo entre Aluno Saber Científico. Assim sendo, neste trabalho somam-se cinco relações importantes ao processo educacional:

1. Aluno Aluno;

2. Aluno Professor;

3. Aluno Tecnologia;

4. Aluno Ambiente;

5. Aluno Saber Científico.

Neste cenário, o professor surge, juntamente com a escola, para decidir o melhor estilo de trabalho entre os saberes do senso comum e científico na comunidade escolar. Esse conjunto de ações propõe como organizar o processo de ensino do saber observado.

Tais ações, embasadas por atividades experimentais, têm a intenção de oferecer condições para que os estudantes em geral consigam ver uma dada situação com o mesmo olhar do professor, induzindo-os a possíveis relações ou variáveis de interesse.

Muitas das dificuldades que ocorrem no processo de ensino-aprendizagem, tem sua origem nas diferentes interpretações que os estudantes elaboram sobre o que veem. Nossa prática como professor tem mostrado que os estudantes, relutam em perguntar os significados das coisas [...] originando interpretações na maioria das vezes totalmente fora de sentido. Por vezes descrições do professor levam o estudante a imaginar coisas desvirtuadas do objeto enfocado.

(ALVES FILHO, 2000a p. 275) 
Durante o processo de desenvolvimento deste trabalho, houve forte influência de três pensadores: Alves Filho (2000a), Maxwell (1995) e David Ausubel (1968 apud PEDUZZI, 1981). Alves Filho, ao definir a importância vinculada ao processo de Atividades Experimentais, afirma que:

A atividade experimental deve ser entendida como um objeto didático, produto de uma Transposição Didática de concepções construtivistas da experimentação e do método experimental, e não mais um objeto a ensinar. Como objeto didático sua estrutura deve agregar características de versatilidade, de modo a permitir que seu papel mediador se apresente em qualquer tempo e nos mais diferentes momentos do diálogo sobre o saber no processo ensino-aprendizagem. E, principalmente, é um objeto de ação que, manipulado didaticamente pelo professor, irá se inserir no discurso construtivista facilitando a indução do fenômeno didático que objetiva o ensino de saberes.

(ALVES FILHO, 2000a p.262- 263)

De maneira complementar, Maxwell contribui ao tratar da relação do aprendizado com a complexidade dos experimentos trabalhados.

Exibir experimentos ilustrativos, encorajar outros a fazê-los e cultivar de todas as maneiras as ideias que eles iluminam são uma importante parte de nosso trabalho. Quanto mais simples os materiais de um exemplo ilustrativo e quanto mais familiares eles forem para os estudantes, provavelmente maior será a sua aquisição das ideias que o experimento pretende demonstrar. $\mathrm{O}$ valor educacional de tais experimentos é inversamente proporcional à complexidade do aparato. O estudante que usa aparelhos caseiros, que frequentemente não funcionam direito, em geral aprendem mais do que aquele que utiliza instrumentos cuidadosamente ajustados, nos quais ele confia cegamente, e os quais ele não se atreve a desmontar. É extremamente necessário que aqueles que estão tentando ler dos livros os fatos das ciências físicas possam ser habilitados, com a ajuda de alguns exemplos ilustrativos, a reconhecer estes fatos quando os encontram mundo afora.

(MAXWELL, 1995 p.242-243)

Por fim, a contribuição de David Ausubel, ao tratar de sua teoria psicológica conhecida como aprendizagem significativa, desvenda uma verdade inquietante a respeito do real aprendizado realizado pelos alunos:

Assim, independentemente de quão potencialmente significativo é o material a ser aprendido, se a intenção do aprendiz é memorizá-lo arbitraria e literalmente, tanto o processo de aprendizagem como a aprendizagem serão mecânicos ou sem significado. Do mesmo modo, independentemente de quão predisposto para aprender estiver o aprendiz, nem o processo nem a aprendizagem serão significativos se o material não for potencialmente sig- 
nificativo para ele.

(AUSUBEL, 1968 apud PEDUZZI, 1981, p.8-9)

Dentro desta concepção, suprimir do processo educativo a disposição discente em dar seguimento ao propósito pedagógico previamente estipulado pelo professor é no mínimo ingênuo. Por mais que os alunos estejam inseridos num contexto educacional que valoriza suas ações e ideias, se ele não estiver disposto a participar, todo o processo de aprendizagem poderá ser mecânico e sem sentido.

\section{A TECNOLOGIA UTILIZADA}

O Arduino é uma plataforma de prototipagem eletrônica de hardware e software de código mundialmente aberto, criado por volta de 2005 na Itália pelo professor Massimo Banzi do Interaction Design Institute Ivrea. Hoje encontra-se popularmente consolidado, principalmente entre os engenheiros e técnicos em eletrônica (SITE ARDUINO, 2019).

Por possuir código aberto, o Arduino se beneficia de constantes contribuições de pessoas que refinam seu código por meio de exemplos, tutoriais, fóruns e grupos em todo o mundo. Deste modo, as novidades introduzidas ampliam cada vez mais suas possibilidades de aplicação (ibid).

Quando se trata da Impressão 3D, se faz importante compreender que todo modelo é uma representação parcial da realidade. Studer, Benjamins e Fensel (1998) ressaltam que os modelos são apenas uma boa aproximação da realidade e que, no caso de modelos de impressões 3D, a peça possui algumas características que se aproximam do objeto desejado, deixando evidente que sempre há características impossíveis de serem reproduzidas.

A Tecnologia de Impressão 3D oferece uma boa alternativa na construção de modelos tridimensionais. No modo FMD (Fusion Deposition Modeling), utilizado neste trabalho, os objetos são moldados por meio do depósito de sucessivas camadas de material plástico PLA (termoplástico biodegradável derivado do amido de milho, raízes de mandioca e cana) aquecido previamente em uma pequena câmara pressurizada.

Com essa tecnologia se constrói um objeto tridimensional em um modelo computacional, por meio de softwares próprios. Tanto o software quanto os modelos computacionais prontos podem ser encontrados gratuitamente na internet. Outra forma de se obter uma configuração 3D para impressão provém de scanners tridimensionais.

A versatilidade da impressão 3D impulsiona a criatividade dos alunos na resolução de problemas. Para a Física, a visualização de conceitos é essencial para o progresso intelectual dos alunos, possibilitando trabalhar atividades experimentais mais eficazes ao ensino (OLIVEIRA et al., 2017). O aluno pode ser constantemente desafiado ao envolvimento ativo no decorrer da aula.

O Raspberry Pi é uma pequena placa eletrônica, com a capacidade de um pequeno computador com múltiplas funções, e conta com wifi e bluetooh. Existem diversos sistemas operacionais configurados para sua instalação. Pode ser conectado a um monitor e anexado a um teclado e mouse. Sua origem vem de uma instituição de caridade no Reino Unido com o ideal de disseminar recursos digitais em escala mundial, fornecendo computadores de baixo custo e alto desempenho, ajudando as pessoas a estudarem computação e criação 
digital (SITE RASPBERRY PI, 2019).

\section{Trabalho proposto}

A sequência didática propôs um encontro por semana, somando quatro encontros de duas horas cada. É apresentado a seguir um quadro (tabela 1) que resume o programa de cada um dos encontros citados nos anexos.

Tabela 1: Sequência proposta

\begin{tabular}{|c|l|}
\hline encontros & Programa de atividades \\
\hline Primeiro & $\begin{array}{l}\text { - Explicação o papel da memória, da atenção, dos sentidos e } \\
\text { percepções;- Apresentação das tecnologias utilizadas; - Atividade } \\
\text { prática: Ligar um LED com Arduino. }\end{array}$ \\
\hline Segundo & $\begin{array}{l}\text { - Levantamento do senso comum com a questão: Vocês confiam } \\
\text { nos seus cinco sentidos ? -Fazer a explicação dos conceitos } \\
\text { científicos vinculados aos sentidos humanos: audição, tato, visão, } \\
\text { olfato e paladar; - Atividade prática: Controlar um servo motor } \\
\text { com três botões ligados ao Arduino. }\end{array}$ \\
\hline Terceiro & $\begin{array}{l}\text { - Apresentação das relações entre ângulos, força resultante, braço } \\
\text { de alavanca e momento de uma força resultante; - Atividade } \\
\text { prática: Construir um guindaste com partes impressas em 3D, } \\
\text { controlado pelo circuito trabalhado no encontro anterior. }\end{array}$ \\
\hline Quarto & $\begin{array}{l}\text { - Inserir a lógica de programação com o programa Scratch insta- } \\
\text { lado em um Raspberry PI. - Permitir que os alunos construam e } \\
\text { controlem um braço robótico com Arduino. }\end{array}$ \\
\hline
\end{tabular}

Esta sequência didática foi aplicada em um teste piloto a 12 alunos provenientes do $5 \mathrm{o}$ ao 90 ano de uma escola particular, na cidade de São José - SC. No entanto, as análises destes encontros ficam para um outro artigo.

\section{IV.1. Preparo do ambiente}

Em um ambiente de ensino com muitos instrumentos, corre-se o risco de dispersar a atenção do aluno. Neste caso, a dinâmica da aula passa a ser de suma importância, onde os elementos constitutivos do ambiente de estudo devem ser dados de maneira gradual, seguindo um cronograma pré-determinado (OLIVEIRA et al., 2017). Cabe salientar que este cronograma precisa oferecer condições de maleabilidade, devido às diferentes características de cada novo encontro.

Os estímulos precisam ser direcionados para um objetivo comum (ALVES FILHO, 2000b) e facilitar o alcance das novas descobertas, permitindo que os alunos explorem os limites das atividades experimentais em novas aplicações, fato inovador inexistente no método tradicional (OLIVEIRA et al., 2017).

Supõe-se que uma sala de aula configurada de maneira a favorecer as cinco relações: aluno -tecnologia, aluno - professor, aluno - aluno, aluno - ambiente e aluno - saber científico 


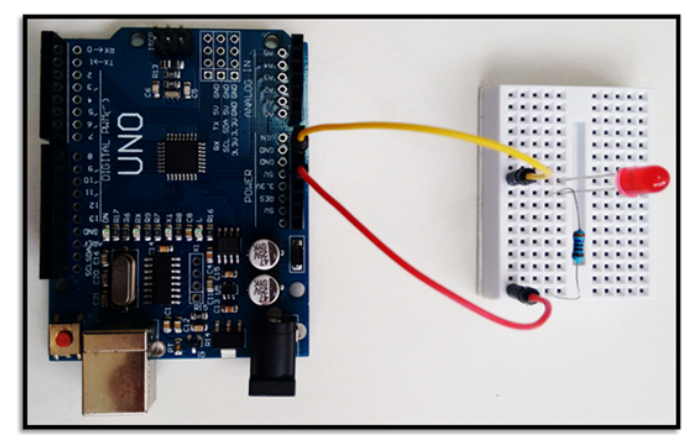

Figura 1: Circuito com Resistor e LED. Fonte: O autor 2019.

não siga o padrão disposto em filas. Os estudantes, neste caso, podem ser organizados em pequenos grupos e, na sala, ter um quadro branco e projetor de slides utilizados em momentos chaves, como por exemplo, na introdução da aula ou nas explicações do funcionamento das tecnologias e suas aplicações.

\section{IV.2. Sequência Didática}

Na presente seção, o leitor encontrará um resumo de como aplicar as aulas com o aparato experimental utilizado. Os dados mais detalhados encontram-se nos planos de ensino (APÊNDICE).

No primeiro encontro, sugere-se que os alunos manuseiem o Raspberry Pi, algumas peças impressas em 3D e o Arduino. Com isso, é possível dar início às práticas, motivandoos a montarem um circuito com um resistor e um LED em uma protoboard, controlado por Arduino (Figura 1).

No segundo encontro, para conscientizar os estudantes que os cinco sentidos humanos possuem limites, podem ser apresentadas atividades experimentais que evidenciem esta realidade. Na sequência, é possível afirmar que as descobertas científico-tecnológicas auxiliam nesta questão. É apresentado a seguir um quadro (tabela 2) que resume o proposto para cada um dos sentidos.

Tabela 2: Atividades aplicadas com os sentidos

\begin{tabular}{|l|l|}
\hline Sentidos & Atividade aplicada \\
\hline Visão & $\begin{array}{l}\text { Infravermelho captado por uma câmera de celular e não por } \\
\text { nossos olhos. }\end{array}$ \\
\hline Olfato & Perfumes intensos dificultam perceber perfumes suaves. \\
\hline Paladar & $\begin{array}{l}\text { Ao experimentar limão e beber água pura, percebe-se um sabor } \\
\text { no líquido. }\end{array}$ \\
\hline Audição & $\begin{array}{l}\text { Variando a frequência de } 20 \text { a } 20.000 \mathrm{~Hz} \text { com um aplicativo para } \\
\text { smartphone verifica-se discrepâncias auditivas. }\end{array}$ \\
\hline Tato & $\begin{array}{l}\text { Ao tocar um metal e uma madeira confunde-se a percepção de } \\
\text { quente e frio. }\end{array}$ \\
\hline
\end{tabular}

Assim, é possível chamar a atenção do aluno, inserindo o conteúdo no dia-a-dia e nas 


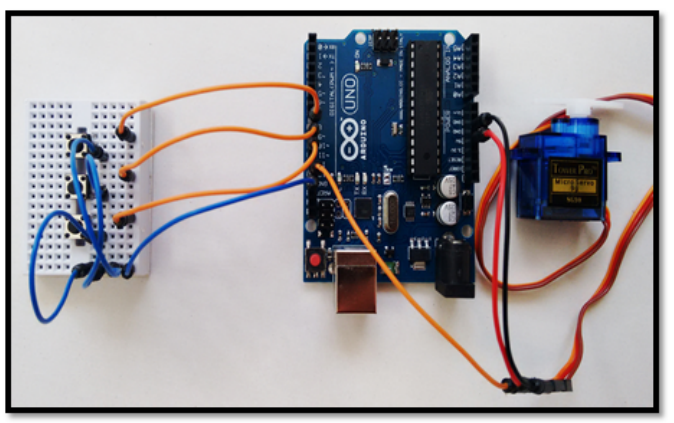

Figura 2: Servo motor controlado por Arduino. Fonte: O autor 2019.

experiências vividas do indivíduo. Desta forma, o aluno não mais levanta questões como: "Por que estou aprendendo isso? " ou "Onde e quando usarei isto em minha vida? ". Na verdade, o aluno dá significado ao que está sendo aprendido. Inverte-se, então, a questão para: "Por que não aprender isso?"

Tendo aguçado a curiosidade discente, pode-se dar prosseguimento à aula, permitindo a construção de um circuito mais complexo, composto por um servo motor controlado por três botões ligados ao Arduino já programado (Figura 2).

Com este aparato, é possível verificar que o servo motor descreve um movimento preciso, respondendo ao ângulo inserido no programa fonte. Cada um dos três botões ordena o movimento para um valor pré-definido.

Após terem se apropriado deste funcionamento, pode-se partir para a próxima etapa. No terceiro encontro, os alunos terão contato com algumas partes do braço robótico, as quais serão usadas para a construção de um guindaste (Figura 3), montado por eles, e controlado com o circuito da aula anterior.
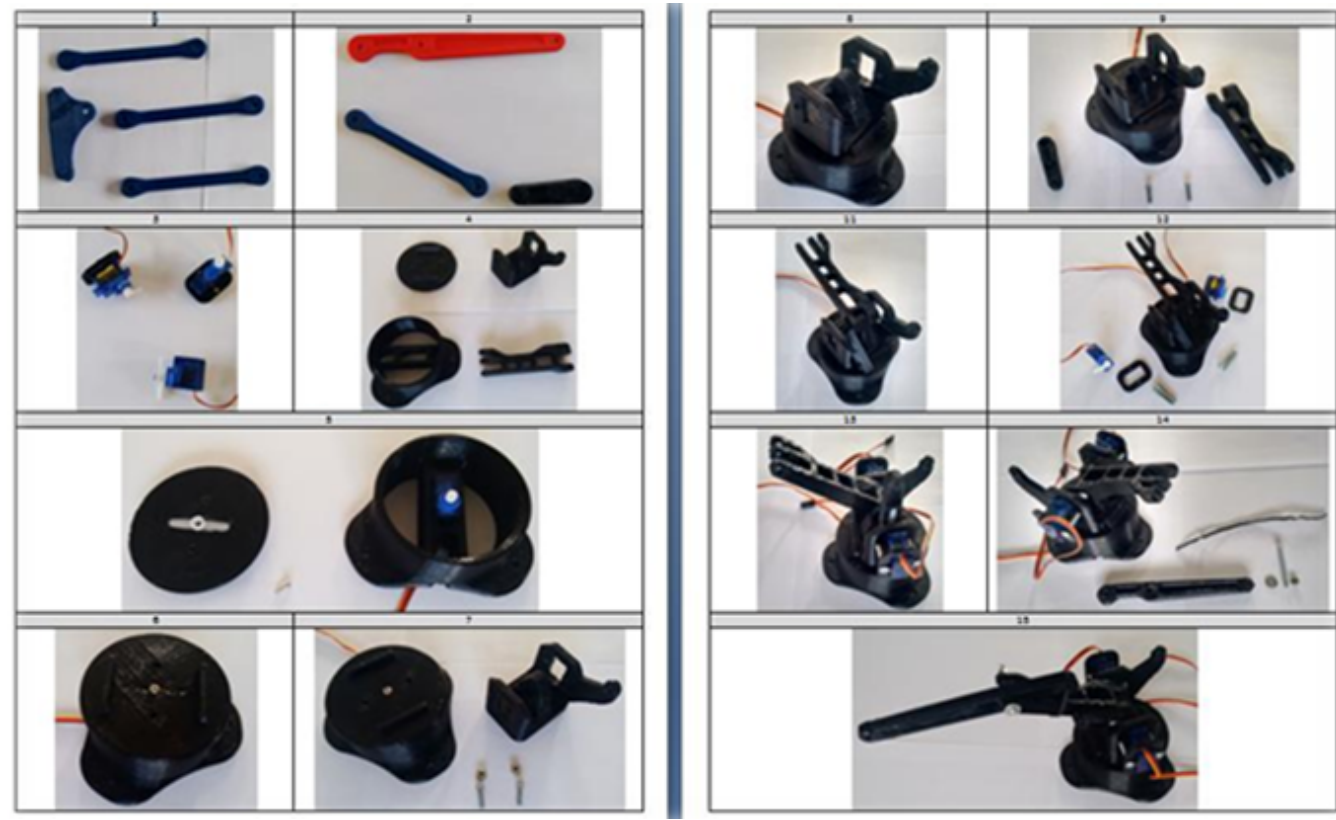

Figura 3: Conjunto do Guindaste Montado Pelos Alunos. Fonte: O autor 2019.

A montagem, ativação e manejo do guindaste consumirá todo o período da aula, pois o 
professor poderá fazer alterações nos ângulos do código fonte, para já ir inserindo-os no universo da programação.

Ao chegar no quarto encontro, o guindaste construído na aula passada será desmontado e reconstruído na forma do braço robótico. Sua ativação será feita pelo professor, com comandos pré-estipulados, por meio do programa fonte do Arduino (Figura 4). Nada impede que os alunos interessados participem deste processo.

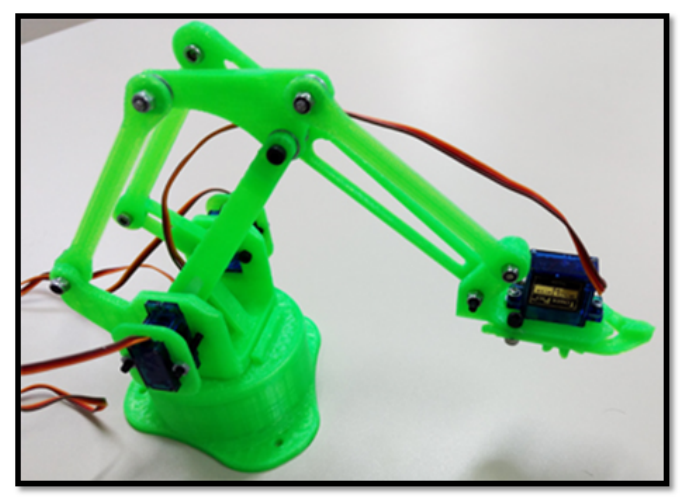

Figura 4: Braço Robótico montado pelos alunos. Fonte: O autor 2019.

Neste último encontro, cabe ainda desenvolver uma sequência lógica no software Scratch, inserido na plataforma do Raspberry Pi. O Scratch é uma linguagem de programação projetada pelo grupo Lifelong Kindergarten no MIT Media Lab (SITE SCRATCH, 2019).

Trata-se de uma ferramenta que pode ser usada para computação criativa. Com esta linguagem de programação, gratuita e disponível ${ }^{1}$, as pessoas podem criar animações, histórias, jogos e compartilhar esses projetos com outras pessoas em uma comunidade on-line. Desta forma, é possível aumentar a familiaridade com a programação computacional por meio de atividades que encorajam os alunos a programar suas próprias estórias, e assim, exercitam sua criatividade e raciocínio lógico, além de aprender a trabalhar em grupo, algo essencial para o mundo atual (ibid).

Em suma, para realização deste trabalho, os materiais utilizados foram: notebook, Arduino com fonte de alimentação, protoboard, LED, botões, servo motor, braço robótico impresso em 3D e Raspberry PI com o programa Scratch instalado. Caso haja dificuldade em encontrá-los todos, a seção seguinte trata de outros caminhos que podem auxiliar nesta questão.

\section{DICAS PARA REALIZAR A SEQUÊNCIA DIDÁTICA}

O Raspberry Pi pode ser substituído por um computador ou notebook. Porém, se há o desejo de fazer uso dessa plataforma eletrônica, a configuração do sistema operacional para fazê-lo funcionar com o software Scratch pode ser encontrada com certa facilidade no mundo virtual $^{2}$.

Com relação à impressão 3D, poucos tem acesso ao equipamento e possuem a habilidade necessária para projetar um braço robótico. Para tanto, como material suplementar pode-se

\footnotetext{
${ }^{1}$ http://scratch.mit.edu.

${ }^{2}$ https://www.mundotibrasil.com.br/como-baixar-e-instalar-o-sistema-operacional-no-raspberry-pi-3/.
} 
utilizar o projeto do braço oferecido em sites específicos ${ }^{3}$ (figura 5). Cabe ressaltar, que existem outas opções para adquirir o braço já pronto ${ }^{4}$.

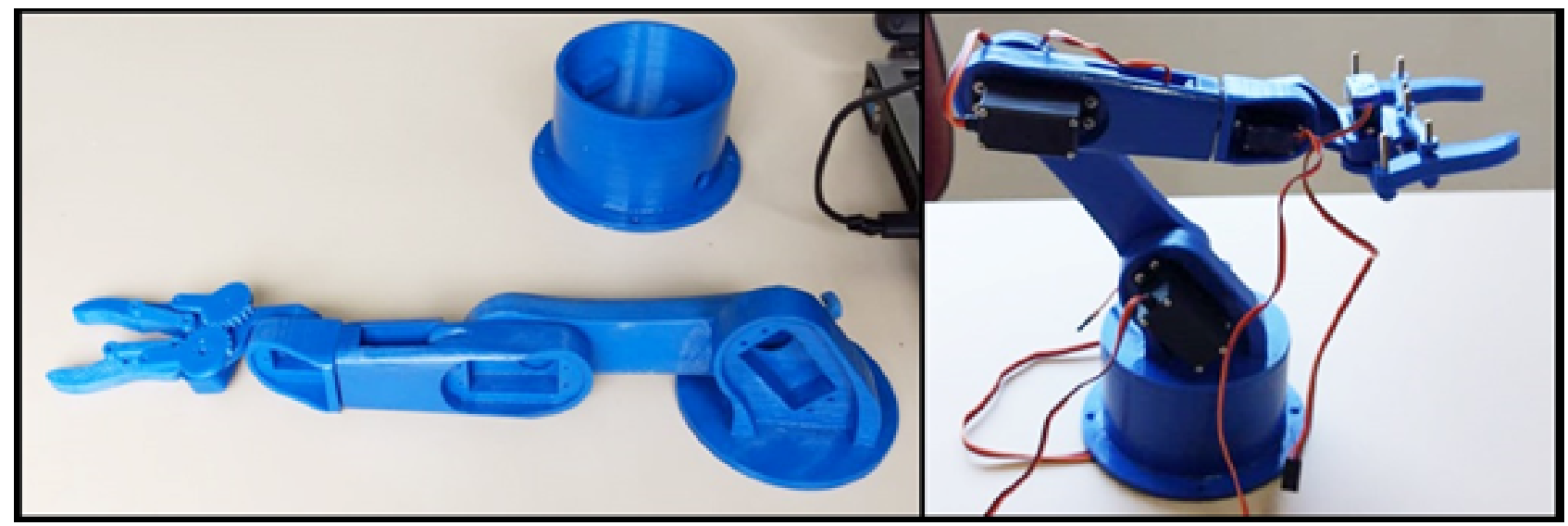

Figura 5: Opção de braço robótico. Fonte: O autor 2019.

Ainda com relação ao software Scratch utilizado, é importante dizer que não foi utilizada a versão modificada, que interage com o Arduino, mas caso o leitor tenha interesse de seguir este caminho, há sites especializados neste assunto ${ }^{5}$.

Fica como sugestão outra forma de programar o Arduino semelhante ao Scratch, porém integrada diretamente na IDE deste equipamento, chamado ArduBlock ${ }^{6}$.

Os códigos do programa fonte Arduino utilizados, na montagem do circuito com um resistor, um LED e uma protoboard (Figura 1), são facilmente encontrados no próprio site do Arduino ${ }^{7}$.

Para colocar o guindaste (Figura 2) constituído por um servo motor e três botões para funcionar, basta procurar por sites que falam do controle destes equipamentos ${ }^{8}$.

Para fazer o braço robótico funcionar, basta inserir códigos de movimentos para cada servo motor ${ }^{9}$.

\section{CONSIDERAÇÕES FINAIS}

A sequência didática fez uso de artefatos tecnológicos que, seguindo uma ordem préestipulada, motivou o estudo de conteúdos de física mediados por atividades experimentais construídas e manipuladas pelo aluno. A intenção foi estimular os alunos por meio de inovações tecnológicas conduzidas por metodologias mais ativas. Neste sentido, foram abordados conceitos de momento de uma força e lógica, procurando motivar o diálogo Aluno Aluno; Aluno Tecnologia; Aluno Ambiente; Aluno Saber e Aluno Professor.

\footnotetext{
${ }^{3}$ https:/ / howtomechatronics.com/tutorials/arduino/diy-arduino-robot-arm-with-smartphone-control/

${ }^{4}$ https:/ / produto.mercadolivre.com.br/MLB-1011158920-kit-braco-robotico-educacional-para-arduino-semservos-_JM.

${ }^{5}$ http://s4a.cat/.

${ }^{6}$ http:/ / teachduino.ufsc.br/ardublock-edicao-para-fisica/.

${ }^{7}$ https://www.arduino.cc/en/tutorial/blink.

${ }^{8}$ https:/ / www.arduinoecia.com.br/2013/06/controlando-um-servo.html.

${ }^{9}$ https:/ / www.filipeflop.com/blog/micro-servo-motor-9g-sg90-com-arduino-uno/.
} 
A tecnologia foi tratada de maneira a ser facilmente utilizada e compreendida pelos alunos, entendida como parte de um todo. Estas características objetivam enriquecer as interações pertinentes e a potencialização do processo de ensino e aprendizagem.

Quanto às motivações e estímulos didáticos destinados ao interesse do aluno pelo aprendizado, esse projeto foi em busca da inovação pedagógica, ao inserir gradativamente as tecnologias no contexto educacional, do mais simples (ligar um LED) ao mais complexo (controlar um braço robótico).

No que tange ao processo de aprendizagem, há consenso que inovação não é sinônimo de inserção tecnológica, tampouco de novas metodologias. Inovar reflete na necessidade de integrar esses dois mundos. O aluno deve ser o centro do processo, ativo e corresponsável, junto ao professor, pelo processo de aprendizagem. Neste contexto, o professor é visto como alguém que indica o caminho e os objetivos a serem alcançados. Atua como motivador e instrutor, preenche as lacunas conceituais/práticas e direciona os alunos no decorrer das atividades, de modo a potencializar consideravelmente as chances de sucesso no aprendizado (OLIVEIRA et al, 2017).

Ao tratar das dificuldades encontradas na aplicação deste trabalho, o baixo incentivo e descrédito à inovação no contexto escolar brasileiro foi vivenciado nas dificuldades em conseguir instituições interessadas em aplicar a sequência proposta. A falta de parceiros que acreditem no investimento em inovação educacional fez com que não fosse possível planejar e expandir para o ensino médio a presente proposta.

\section{REFERÊNCIAS}

ALVES FILHO, P.J. Atividades Experimentais: do Método à Prática Construtivista. 2000. 302 f.. Tese (Doutorado em Educação: Ensino de Ciências Naturais) Universidade Federal de Santa Catarina, 2000a.

ALVES FILHO, P. J. Regras da Transposição Didática Aplicadas ao Laboratório Didático. Caderno Catarinense de Ensino de Física, Florianópolis, v. 17, n. 2, p. 174-188. 2000b.

BENNETT, S., MATON, K., e KERVIN, L. The digital natives debate: A critical review of the evidence. British journal of educational technology, 39(5), 775-786, 2008.

MAXWELL, J. C. Introductory Lecture on Experimental Physics. In: NIVEN, W. D.(Editor) The Scientific Papers of James Clerk Maxwell, Vol. II. Paris: Librarie Scientifique J.Herman, 1995.

OLIVEIRA, L. M.; PEREIRA, L. M. F.; SOUZA, M. M.; EVANGELISTA, F. L.; ARAGÃO, P,A,F. Projeto tecnológico de ensino de física e matemática sob a ótica da neuroeducação. In: Foz do Iguaçu. VII Congresso Internacional de Conhecimento e Inovação. Ciki, 2017.

OTERO, V., PERESSINI, D., MEYMARIS, K. A., FORD, P., GARVIN, T., HARLOW, D., \& MEARS, C. Integrating technology into teacher education: A critical framework for implementing reform. Journal of Teacher Education, 56(1), 8-2, 3, 2005. 
PEDUZZI, S.S. Uma Abordagem Ausubeliana ao Ensino de Eletricidade e Magnetismo em Nível Universitário Básico. 1981. 97 f.. Dissertação (Mestrado em Física) Universidade Federal do Rio Grande do Sul, Instituto de Física, 1981.

PRENSKY, M. Digital natives, digital immigrants part 1. On the horizon, 9(5), 1-6, 2001.

SAMPAIO, M. N. LEITE, L. S. Alfabetização tecnológica do professor. Ed. Petrópolis, RJ: Vozes, 2010.

SITE ARDUINO. Disponível em: < https:/ /www.arduino.cc/ > Acesso em 29 de Jan. 2019.

SITE RASPBERRY PI. Disponível em: < https:/ /www.raspberrypi.org/products/raspberrypi-3-model-b/ > Acesso em 29 de Jan. 2019.

SITE SCRATCH. Disponível em: < https://scratch.mit.edu/parents/ > Acesso em 29 de Jan. 2019.

STUDER, R., RICHARD B., V. e FENSEL, D. Knowledge Engineering: Principles and Methods. Data \& Knowledge Engineering, 25, 161-197, 1998. 
Materiais didáticos para o ensino de física no nível fundamental por meio

A. Planejamento das Aulas Referentes a sequência didática 


\section{PLANO DE AULA PARA O PRIMEIRO ENCONTRO}

Professor:

Turma:

Instituição:

Carga horária:
Data:

Série:

Turno:

Título: O aprendizado na perspectiva da neurociência.

\section{Objetivos de Ensino:}

- Explicar o papel da memória, da atenção, dos sentidos e percepções;

- Apresentar das tecnologias utilizadas;

- Ligar um LED com Arduino.

Núcleo Conceitual: Entender como se dá o aprendizado da perspectiva da neurociência cognitiva (COSENZA E GUERRA, 2011; OLIVEIRA et al., 2017).

Metodologia: Este encontro foi estruturado seguindo os seguintes critérios:

- A aula é iniciada de forma conceitual, com apresentação de slides, para ajudar a entender como ocorre o aprendizado segundo a neurociência cognitiva.

- Apresentação das novas tecnologias utilizadas durante as aulas;

- Motivá-los a resolverem em grupo um desafio tecnológico com o mínimo de auxílio docente.

Recursos Didáticos: Computador; Datashow; Quadro e pincel; LED; Protoboard; Fios e Arduino.

\section{Procedimento Didático:}

$1^{\circ}$ ação:

Tempo previsto: 40 minutos

Dinâmica: Fazer uma introdução a fim de conscientizar os alunos sobre o universo da aprendizagem, expondo que há várias formas de ensinar e aprender, explicando qual o papel da memória, da atenção, dos sentidos e percepções.

$2^{\circ}$ ação:

Tempo previsto: 40 minutos.

Dinâmica: Evidenciar o fato que a aprendizagem não ocorre só no mundo das ideias, mas também no mundo físico, por meio de novas comunicações entre regiões cerebrais ao longo do tempo. Este fato explica a dificuldade em iniciar novos estudos.

$3^{\circ}$ ação:

Tempo previsto: 40 minutos.

Dinâmica: Os alunos são apresentados aos materiais, onde podem ver e manusear o Raspberry Pi, algumas peças impressas em 3D e o Arduino. Com isso, se dá o início das práticas, motivando-os a montarem um circuito com um resistor e um Led em uma protoboard, controlado por Arduino (Figura 1).

Avaliação:

- Critérios: São avaliados aspectos como mudança nas respostas devido a discussão, o comportamento dos alunos do ponto de vista da interação com os colegas, verificando se existe interação, discussão e se isso refletiu nos resultados.

- Instrumentos de Avaliação: A avaliação é feita de maneira coletiva, ou seja, a ideia não é avaliar individualmente os alunos, mas o todo, e desta forma, verificar se os objetivos de ensino foram alcançados.

Referências:

COSENZA, R. e GUERRA, L. Neurociência e Educação: como o cérebro aprende. Porto Alegre: Artmed, 2011.

OLIVEIRA, L. M.; PEREIRA, L. M. F.; SOUZA, M. M.; EVANGELISTA, F. L.; ARAGÃO, P,A,F. Projeto tecnológico de ensino de física e matemática sob a ótica da neuroeducação. In: Foz do Iguaçu. VII Congresso Internacional de Conhecimento e Inovação. Ciki, 2017.

\section{Observações ocorridas durante ou após as aulas:}




\section{PLANO DE AULA PARA O SEGUNDO ENCONTRO}

\section{Professor:}

Turma:

Instituição:

Carga horária:
Data:

Série:

Turno:

Título: Os limites dos sentidos humanos e o auxílio das tecnologias.

Objetivos de Ensino:

-Abordar conceitos científicos a partir dos sentidos humanos: audição, tato, visão, olfato e paladar;

- Controlar um servo motor com três botões ligados ao Arduino.

Núcleo Conceitual: A ciência envolvida nos cinco sentidos humanos é uma boa justificativa para o estudo científico e tecnológico (OLIVEIRA et al., 2017). Uma boa audição humana, consegue captar frequências no intervalo de 20 e $20.000 \mathrm{~Hz}$. O tato pode ser facilmente enganado ao ter contato com uma barra de ferro e uma almofada. Neste caso, a temperatura dos materiais, estando em equilíbrio térmico com o ambiente, estão a mesma temperatura, mas o tato leva a perceber o ferro mais gelado. Isso ocorre pois o calor específico do ferro é menor que o da almofada, proporcionando um maior fluxo de calor no ferro, dando a impressão de estar com menor temperatura. A visão humana capta comprimento de ondas que variam de 380 a $740 \mathrm{~nm}$ e isto significa que percebemos as cores entre o violeta e o vermelho. $\mathrm{O}$ olfato quando submetido durante longos períodos, diminui a sensibilidade. $\mathrm{O}$ paladar pode ser facilmente enganado ao ser submetido a sabores muito intensos, como o azedo do limão (ALVARENGA, 2014; GUALTER, NEWTON e HELOU 2007; SAMPAIO e CALÇADA, 2005).

Estas descobertas trazem implicitamente uma característica emocional, envolvendo o estudante na busca por respostas pelos meios científicos (CUSTÓDIO FILHO, 2007). Este processo educacional supera os estigmas criados socialmente e cognitivamente, que atribuem à física um caráter incompreensível e desconexo da realidade, agregando ao estudo uma sensação agradável de satisfação ao sucesso do aprendizado.

Metodologia: Este encontro foi estruturado seguindo os seguintes critérios:

- Revisão dos o assunto do encontro anterior;

- Exposição os limites dos 5 sentidos humanos;

- Resolução em grupo um desafio tecnológico sobre ângulos e plano cartesiano, com o mínimo de auxílio docente, por meio da ativação de um servo motor por Arduino já programado.

Recursos Didáticos: Computador; Datashow; Quadro e pincel; Transferidor; Botões; Servo motor; Protoboard; Fios e Arduino.

\section{Procedimento Didático:}

$1^{\circ}$ ação:

Tempo previsto: 40 minutos

Dinâmica: Abordar os conceitos científicos a partir dos sentidos humanos: audição, tato, visão, olfato e paladar. Iniciar o encontro questionando: Vocês confiam nos seus sentidos?

O intuito é conscientizá-los que os 5 sentidos humanos possuem limites e as descobertas científico-tecnológicas auxiliam nesta questão:

- Visão: Infravermelho captado por uma câmera de celular e não por nossos olhos;

- Olfato: Perfumes intensos dificultam perceber perfumes suaves;

- Paladar: Ao experimentar limão e beber água pura, percebe-se um sabor no líquido;

- Audição: Variando a frequência de 20 a $20.000 \mathrm{~Hz}$ com um aplicativo para smartphone verifica-se discrepâncias auditivas;

- Tato: Ao tocar um metal e uma madeira confunde-se a percepção de quente e frio.

$2^{o}$ ação:

Tempo previsto: 40 minutos.

Dinâmica: Ao dar prosseguimento a aula, explica-se o funcionamento do servo motor, solicitando sua conexão a um circuito controlado por três botões ligados ao Arduino já programado (Figura 2). Ao acionar os botões, é possível perceber que o servo motor realiza movimentos precisos pré-programados. Neste momento cabe uma intervenção teórica sobre ângulos e plano cartesiano, mostrando que o servo motor funciona com ângulos e a impressora 3D com plano cartesiano.

$3^{\circ}$ ação:

Tempo previsto: 40 minutos.

Dinâmica: Ao fim do encontro, com o transferidor os alunos podem medir os ângulos de rotação do servo motor e os compararam com os valores expressos na linguagem de programação exibida a eles por meio de slides. 
Avaliação:

- Critérios: Capacidade de relacionar os conceitos vistos nas aulas anteriores com os experimentos observados e explicar de uma maneira didática para outros colegas o que é observado.

- Instrumentos de Avaliação: A avaliação é feita de maneira coletiva, e desta forma, verificar se os objetivos de ensino foram alcançados.

\section{Referências:}

ALVARENGA, Beatriz; MÁXIMO, Antônio. Física-Contexto e Aplicações. São Paulo: Scipione, 2014.

CUSTÓDIO FILHO, J. F. Explicando Explicações na Educação Científica: Domínio Cognitivo, Status Afetivo e Sentimento de Entendimento. 249 f. Tese (Doutorado) - Curso de Centro de Ciências Físicas e Matemáticas Centro de Ciências da Educação, Programa de Pós-graduação em Educação Científica e Tecnológica, Universidade Federal de Santa Catarina, Florianópolis, 2007.

GUALTER, NEWTON e HELOU. Tópicos de Física 1. São Paulo: Saraiva, 2007.

OLIVEIRA, L. M.; PEREIRA, L. M. F.; SOUZA, M. M.; EVANGELISTA, F. L.; ARAGÃO, P,A,F. Projeto tecnológico de ensino de física e matemática sob a ótica da neuroeducação. In: Foz do Iguaçu. VII Congresso Internacional de Conhecimento e Inovação. Ciki, 2017.

SAMPAIO, Jose Luiz; CALCCADA, Caio Sérgio. Física: volume único. São Paulo: Atual, 2005.

Observações ocorridas durante ou após as aulas: 


\section{PLANO DE AULA PARA O TERCEIRO ENCONTRO}

\section{Professor:}

Turma:

\section{Instituição:}

Carga horária:
Data:

Série:

Turno:

Título: A Física de um guindaste

\section{Objetivos de Ensino:}

- Relacionar ângulos, força mecânica resultante, momento escalar de uma força em relação a um eixo e alavanca;

- Construir um guindaste com partes impressas em 3D, controlado pelo circuito trabalhado no encontro anterior.

Núcleo Conceitual: Ângulos podem ser definidos como duas semirretas com a mesma origem no vértice. No ensino médio, normalmente são trabalhados em grau $\left(^{\circ}\right)$ ou radiano (rad). Força é uma grandeza da Física cujo efeito dinâmico causa a aceleração, porém, o somatório das forças, resultado da soma vetorial, pode acarretar em aceleração igual a zero. Momento Escalar de uma Força em relação a um eixo é o produto da intensidade da força por seu braço em relação ao ponto fixo. Quando um corpo extenso se encontra em condições de equilíbrio translacional e rotacional a resultante das forças e a soma algébrica dos momentos escalares serão zero. As alavancas consistem em barras utilizadas geralmente para ampliar o efeito de forças aplicadas nesta barra, classificas como interfixa, inter-resistente e interpotente (ALVARENGA, 2014; GUALTER, NEWTON e HELOU 2007; SAMPAIO e CALÇADA, 2005).

Metodologia: Este encontro foi estruturado seguindo os seguintes critérios:

- Explicação dos assuntos inerentes aos ângulos, Força Mecânica Resultante, Momento Escalar de uma Força em relação a um Eixo e Alavanca;

- Resolução, juntamente com os alunos, de alguns exercícios propostos em uma lista projetada por slides;

- Motivação dos alunos na montarem e controle de um protótipo de guindaste com o Arduino;

Recursos Didáticos: Computador; Datashow; Quadro e pincel; Peças em 3D; Protoboard; Fios e Arduino.

\section{Procedimento Didático:}

$1^{\circ}$ ação:

Tempo previsto: 40 minutos

Dinâmica: Tratar da relação entre ângulos, Força Mecânica Resultante, Momento Escalar de uma Força em relação a um Eixo e Alavanca.

Submeter os alunos a algumas questões no projetor de slides, procurando motivar a discussão em sala favorecer as 5 mediações pedagógicas citadas.

1) Qual dos ângulos torna mais fácil suportar o peso de uma cadeira erguida do chão com os braços estendidos?
a) $0^{\circ}$
b) $30^{\circ}$
c) $45^{\circ}$
d) $70^{\circ}$

2) Ao suportar o peso de uma cadeira erguida do chão, qual posição dos braços torna mais difícil esta tarefa?

a) Braços totalmente estendidos;

b) Braços semi-estendidos;

c) Braços formando um ângulo de $90^{\circ}$ entre o braço e o antebraço;

d) A posição dos braços não tem influência no esforço realizado.

3) Como um guindaste pode diminuir o esforço feito por ele?

a) trabalhando com ângulo de $0^{\circ}$ colocando o peso a ser erguido na extremidade da sua haste;

b) O esforço de um guindaste não depende do ângulo da haste em que o objeto é içado;

c) Deslocando o objeto no sentido da extremidade para a o centro do guindaste;

d) O esforço de um guindaste não depende da posição em que o objeto é içado.

Caso haja alguma confusão causada pelas falas e discussões simultâneas dos alunos e divergência nas respostas, cabe ao professor auxiliar nas explicações.

$2^{\circ}$ ação:

Tempo previsto: 40 minutos.

Dinâmica: Entregar um conjunto contendo as partes do braço robótico para a construção de um guindaste (Figura 3), que deverá ser montado por eles.

$3^{o}$ ação:

Tempo previsto: 40 minutos. 
Dinâmica: Como conclusão da aula, a fim de revisar os conceitos físicos estudados, o professor pode chamar um aluno a frente. Este segura uma cadeira com os braços estendidos na horizontal. Percebendo sua força para sustentá-la, o professor pergunta aos alunos da sala o que ele poderia fazer para minimizar seu esforço. Esperam-se duas respostas: a primeira refere-se ao flexionar os braços estendidos, afirmando que se ele os aproximar do corpo torna-se mais fácil a sustentação; A segunda trata da inclinação de seus braços estendidos, ao aproximar do ângulo de $90^{\circ}$ reduz o esforço realizado. Desta forma, espera-se que os alunos respondam com sua própria linguagem as relações existentes entre o comprimento da alavanca, o ângulo de inclinação, o peso que ela suporta e a força que ela exerce.

Avaliação:

- Critérios: São avaliados aspectos como mudança nas respostas devido a discussão, assim como o comportamento dos alunos do ponto de vista da interação com os colegas, verificando se existe interação, discussão e se isso refletiu nos resultados.

- Instrumentos de Avaliação: A avaliação é feita de maneira coletiva e, desta forma, verificar se os objetivos de ensino foram alcançados.

Referências:

ALVARENGA, Beatriz; MÁXIMO, Antônio. Física-Contexto e Aplicações. São Paulo: Scipione, 2014.

GUALTER, NEWTON e HELOU. Tópicos de Física 1. São Paulo: Saraiva, 2007.

SAMPAIO, Jose Luiz; CALÇADA, Caio Sérgio. Física: volume único. São Paulo: Atual, 2005.

Observações ocorridas durante ou após as aulas: 


\section{PLANO DE AULA PARA O QUARTO ENCONTRO}

\section{Professor:}

Turma:

Instituição:
Data:

Série:

Turno:

Carga horária:

Título: Construção de um braço robótico e o início de uma sequência lógica

Objetivos de Ensino:

- Inserir a lógica de programação com o programa Scratch instalado em um Raspberry PI.

- Promover a construção e controle de em um braço robótico pelos alunos, com o programa fonte do Arduino.

Núcleo Conceitual: Trabalhar com o software Scratch, significa entrar no mundo que explora um conjunto de programações visuais, focada na criação de uma sequência lógica de animações por um personagem criado pelo próprio aluno. Desta maneira, é facilitada a aprendizagem da lógica de programação (SITE SCRATCH, 2019).

Metodologia: Este encontro foi estruturado seguindo os seguintes critérios:

- Revisão do encontro anterior;

- Construção e controle um braço robótico com Arduino;

- Instalação do teclado, mouse, monitor de computador no Raspberry Pi;

- Realização das atividades usando o software Scratch.

Recursos Didáticos: Computador; Datashow; Quadro e pincel; braço robótico; Protoboard; Fios e Arduino; Raspberry Pi; teclado; mouse; Monitor de computador.

Procedimento Didático:

$1^{\circ}$ ação:

Tempo previsto: 40 minutos

Dinâmica: A partir do guindaste construído na aula passada, propor a construção do braço robótico e sua ativação por meio do Arduino já programado (Figura 4).

$2^{\circ}$ ação:

Tempo previsto: 40 minutos.

Dinâmica: Por ser uma tarefa mais exigente, há necessidade de auxílio constante do professor durante a montagem e programação do Arduino. A proposta da aula é motivá-los a realizar tarefas com o braço robótico, controlando-o através de modificações no programa fonte no notebook, para pegar blocos e mudá-los de lugar, relacionando os conceitos estudados com a prática.

$3^{\circ}$ ação:

Tempo previsto: 40 minutos.

Dinâmica: No decorrer deste encontro, os alunos ainda são convidados a desenvolver uma sequência lógica no software Scratch, inserido na plataforma do Raspberry Pi.

Avaliação:

- Critérios: São avaliados aspectos como mudança nas respostas devido a discussão, o comportamento dos alunos do ponto de vista da interação com os colegas, verificar se existe interação, discussão e se isso refletiu nos resultados.

- Instrumentos de Avaliação: A avaliação é feita de maneira coletiva, a ideia não é avaliar individualmente os alunos, mas o todo, e desta forma, verificar se os objetivos de ensino foram alcançados.

Referências:

SITE SCRATCH. Disponível em: < https://scratch.mit.edu/parents/ > Acesso em 29 de Jan. 2019.

Observações ocorridas durante ou após as aulas: 


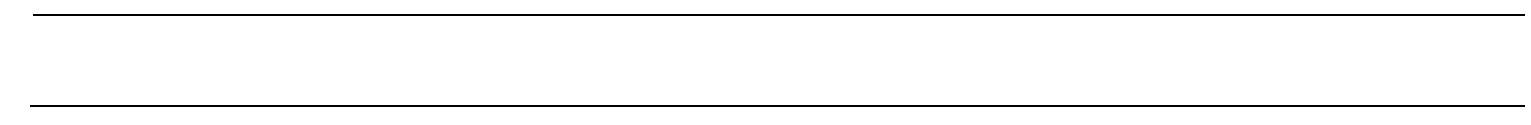

